\title{
POTENCIAL DE MULTIPLICAÇÃO IN VITRO DE CULTIVARES DE AMOREIRA-PRETA ${ }^{1}$
}

\author{
ROBERTO PEDROSO DE OLIVEIRA ${ }^{2}$, ANTONIO FERNANDO PACHECO NINO³ ${ }^{3}$ LETÍCIA VANNI FERREIRA $^{4}$
}

RESUMO - Este trabalho foi realizado com o objetivo de avaliar o potencial de multiplicação in vitro de sete cultivares de amoreirapreta: Brazos, Cherokee, Comanche, Ébano, Guarani, Tupy e Xavante. Utilizou-se protocolo da Embrapa Clima Temperado empregado em laboratórios comerciais. A desinfestação dos explantes foi realizada em soluções à base de álcool e hipoclorito de sódio; a cultura dos meristemas em meio semi-sólido MS com $1 \mathrm{mg} \mathrm{L}^{-1} \mathrm{BAP}, 0,01 \mathrm{mg} \mathrm{L}^{-1}$ ANA e $0,1 \mathrm{mg} \mathrm{L}^{-1} \mathrm{AG}_{3}$; a multiplicação em MS com $0,8 \mathrm{mg} \mathrm{L}^{-1}$ BAP; e o enraizamento em $1 / 2 \mathrm{MS}$ com $0,5 \mathrm{mg} \mathrm{L}^{-1}$ ANA, sempre a $25 \pm 4^{\circ} \mathrm{C}, 20 \mu \mathrm{E} \mathrm{m}^{-2} \mathrm{~s}^{-1}$, e fotoperíodo de 16 horas. Partiu-se de 60 meristemas de cada cultivar, avaliando-se a taxa de multiplicação e os níveis de contaminação, vitrificação e oxidação durante as fases de estabelecimento (60 dias), multiplicação (seis subcultivos de 40 dias) e enraizamento in vitro (30 dias). O número estimado de plantas obtidas por meristema foi de 16.335 para 'Brazos', 24.211 para 'Cherokee', 19.778 para 'Comanche', 106.550 para 'Ébano', 14.275 para 'Guarani', 34.022 para 'Tupy' e 24.651 para 'Xavante'. A quantificação dessa variabilidade de resposta in vitro é importante para o planejamento da produção de mudas de cada cultivar nos laboratórios de micropropagação.

Termos para indexação: Rubus spp., limpeza de patógenos, micropropagação, produção de mudas.

\section{IN VITRO POTENTIAL OF MULTIPLICATION OF BLACKBERRY CULTIVAR}

ABSTRACT - The aim of this work was to evaluate the in vitro potential of multiplication of seven blackberry cultivars: Brazos, Cherokee, Comanche, Ébano, Guarani, Tupy and Xavante. A commercial micropropagation protocol from Embrapa Clima Temperado was used. The explant desinfestation was carried out in solution of alcohol and sodium hypochlorite. The meristem culture was carried out in semi-solid MS medium with $1 \mathrm{mg} \mathrm{L}^{-1} \mathrm{BAP}, 0.01 \mathrm{mg} \mathrm{L}^{-1} \mathrm{ANA}$ and $0.1 \mathrm{mg} \mathrm{L}^{-1} \mathrm{AG}_{3}$; the explants multiplication in MS medium with $0.8 \mathrm{mg} \mathrm{L}^{-1} \mathrm{BAP}$; and the rooting in $1 / 2 \mathrm{MS}$ medium with $0.5 \mathrm{mg} \mathrm{L}^{-1} \mathrm{ANA}$, always at $25 \pm 4^{\circ} \mathrm{C}, 20 \mu \mathrm{E} \mathrm{m}^{-2} \mathrm{~s}^{-1}$ and 16 hours photoperiod. Sixty meristems of each cultivar were used, evaluating the multiplication rate and the level of contamination, vitrification and oxidation during the phases of in vitro establishment (60 days), multiplication (six subcultures of 40 days) and rooting ( 30 days). The estimated number of plants obtained per meristem was 16335 of 'Brazos', 24211 of 'Cherokee', 19778 of 'Comanche', 106550 of 'Ébano', 14275 of 'Guarani', 34022 of 'Tupy' and 24651 of 'Xavante'. The quantification of this in vitro variability response is important to plan the multiplication of the plants of each cultivar in commercial laboratories.

Index terms: Rubus spp., pathogen cleaning, micropropagation, plants production.

\section{INTRODUÇÃO}

A amoreira-preta pertence à família Rosaceae, gênero Rubus, que compreende mais de trezentas espécies nativas da Europa, África, Ásia e América, inclusive do Brasil (Santos et al., 1997). As plantas são de hábito de crescimento arbustivo de porte ereto ou rasteiro, e os frutos são do tipo agregado, com 4 a 7 gramas de peso, sabor ácido a doce-ácido e coloração negra, sendo comercializados in natura ou na forma industrializada (Antunes, 2002). A cultura destaca-se pela grande demanda por mão-de-obra e pela alta rentabilidade por área, tornando-se apropriada para a agricultura familiar, inclusive para sistemas de produção orgânica e agroecológica (Oliveira et al., 2004).

A área cultivada com amoreira-preta vem crescendo nos últimos anos, em função do sabor diferenciado e de suas propriedades nutracêuticas. Atualmente, no mundo, são cultivados aproximadamente 20 mil ha, sendo 38,5\% na Europa, $36 \%$ na América do Norte, $8 \%$ na América Central, $8 \%$ na América do Sul, 7,5\% na Ásia, 1,5\% na Oceania e 0,5\% na África (Clark,
2006). No Brasil, a área cultivada é de aproximadamente 250 ha, com incremento de $5 \%$ ao ano (Oliveira et al., 2004).

Desde 1975, a Embrapa Clima Temperado vem conduzindo um programa de melhoramento genético da amoreira-preta, tendo lançado as cultivares Ébano, em 1981, Tupy, em 1988, Guarani, em 1988, e Xavante, em 2004. Nesse período, também foram introduzidas as cultivares Brazos, da Universidade Texas A\&M, e a 'Comanche' e a 'Cherokee', da Universidade de Arkansas (Santos et al., 1997). As cultivares Tupy, Guarani, Cherokee e Xavante são as mais indicadas para os produtores que objetivam o mercado in natura, devido à menor acidez das frutas, enquanto as cultivares Ébano, Brazos e Comanche, à industrialização. As cultivares Tupy, Guarani, Brazos, Comanche e Cherokee possuem espinhos, enquanto as cultivares Ébano e Xavante não os apresentam, o que facilita os tratos culturais e a colheita, porém, normalmente, diminui a resistência das cultivares ao ataque de pragas. A cultivar Ébano é a que necessita de maior número de horas de frio para produzir, as cultivares Comanche e Cherokee apresentam exigência intermediária, enquanto que a 'Tupy',

(Trabalho 205-07). Recebido em: 29-08-2007. Aceito para publicação em: 12-02-2008.

${ }^{2}$ Eng. Agr., Doutor, Pesquisador da Embrapa Clima Temperado, C. Postal 403, 96001-970 Pelotas-RS. Bolsista do CNPq. Email: rpedroso@cpact.embrapa.br ${ }^{3}$ Técnico de laboratório da Embrapa Clima Temperado. Email: nino@cpact.embrapa.br.

${ }^{4}$ Graduanda em Agronomia. Faculdade de Agronomia Eliseu Maciel (FAEM/UFPel), C. Postal 354, 96010-900 Pelotas-RS. Bolsista FAPERGS. Email: letivf@gmail.com. 
'Guarani', 'Xavante' e 'Brazos' são menos exigentes, podendo ser plantadas em regiões mais quentes (Oliveira et al., 2004).

A propagação da amoreira-preta pode ser realizada por estaquia de raízes, enraizamento de estacas e por cultura de tecidos em laboratórios de micropropagação (Oliveira et al., 2004), sendo este último procedimento o mais seguro para evitar a contaminação por vírus, fungos, bactérias e nematóides (EPPO, 2004).

Há 15 anos, a Embrapa Clima Temperado vem aprimorando protocolo para a micropropagação de cultivares de amoreirapreta. Nesse período, dezenas de milhares de mudas foram produzidas por meio desse sistema, sendo disponibilizadas a produtores de diferentes Estados. Atualmente, vários laboratórios públicos e particulares vêm propagando mudas sob condições in vitro, sendo as matrizes fornecidas pela Embrapa Clima Temperado. Em função de o gênero Rubus ser bastante responsivo in vitro (Babic \& Neskovic, 1984), um único protocolo de micropropagação vem sendo utilizado, com pequenas variações introduzidas por cada laboratório, em função de suas condições locais (Oliveira et al., 2004). Porém, ainda não foi quantificado o comportamento das principais cultivares quanto ao seu potencial de micropropagação, o que é muito importante para a etapa de planejamento da produção nos laboratórios.

Dessa forma, o objetivo deste trabalho foi avaliar e quantificar o potencial de multiplicação in vitro das cultivares de amoreira-preta Brazos, Cherokee, Comanche, Ébano, Guarani, Tupy e Xavante.

\section{MATERIAL E MÉTODOS}

O trabalho foi realizado no laboratório de Cultura de Tecidos da Embrapa Clima Temperado, situado em Pelotas-RS, avaliando sete cultivares de amoreira-preta: Brazos, Cherokee, Comanche, Ébano, Guarani, Tupy e Xavante.

Considerando-se as melhores características de sanidade e de produtividade, ponteiros de ramos recém-brotados na primavera, com aproximadamente $6 \mathrm{~cm}$ de comprimento, foram coletados de cada cultivar, da Coleção de Pequenas Frutas da Embrapa Clima Temperado.

A desinfestação dos brotos foi realizada em soluções compostas por álcool $70 \%$, durante $10-15$ segundos, e hipoclorito de sódio a 1\%, durante 10 minutos. Em seguida, foram lavados três vezes com água destilada e autoclavada, sob condições assépticas.

Em janeiro de 2006, sessenta meristemas $( \pm 0,3 \mathrm{~mm}) \mathrm{de}$ cada cultivar foram isolados em câmara de fluxo laminar, sob lupa estereoscópica com aumento de até 40 vezes, utilizando pinça e bisturi. Em seguida, esses meristemas foram inoculados (Subcultivo 0), individualmente, em tubos de ensaio (15 mm x 150 $\mathrm{mm}$ ) contendo $6 \mathrm{~mL}$ de meio semi-sólido composto pelos sais de MS (Murashige \& Skoog, 1962) acrescido com 0,5 mg L-1 de tiamina, $0,5 \mathrm{mg} \mathrm{L}^{-1}$ de piridoxina, $0,5 \mathrm{mg} \mathrm{L}^{-1}$ de ácido nicotínico, 2 $\mathrm{mg} \mathrm{L}^{-1}$ de glicina, $30 \mathrm{~g} \mathrm{~L}^{-1}$ de sacarose, $100 \mathrm{mg} \mathrm{L}^{-1}$ de myo-inositol, $6 \mathrm{gL}^{-1}$ de ágar, $1 \mathrm{mg} \mathrm{L}^{-1}$ de BAP (6-benzilaminopurina), $0,01 \mathrm{mg} \mathrm{L}^{-1} \mathrm{de}$ ANA (ácido naftalenoacético) e $0,1 \mathrm{mg} \mathrm{L}^{-1} \mathrm{de} \mathrm{AG}_{3}$ (ácido giberélico). Após a adição de ágar, o pH do meio de cultura foi ajustado para 5,9. A autoclavagem foi realizada à temperatura de $121^{\circ} \mathrm{C}$ a $1,5 \mathrm{~atm}$, por 15 minutos. Os meristemas introduzidos in vitro foram mantidos em câmara escura por 36 horas para evitar oxidação. Posteriormente, foram conduzidos à sala de cultura com intensidade luminosa de $20 \mu \mathrm{E} \mathrm{m}^{-2} \mathrm{~s}^{-1}$, temperatura de $25 \pm$ $2^{\circ} \mathrm{C}$ e fotoperíodo de 16 horas.

Após 60 dias, foram escolhidos os explantes mais desenvolvidos de cada cultivar para dar seqüência ao processo de multiplicação. Esses foram transferidos para frascos de vidro (120 mm de altura $\times 50 \mathrm{~mm}$ de diâmetro) contendo $40 \mathrm{~mL}$ do meio de cultura MS suplementado com $0,8 \mathrm{mg} \mathrm{L}^{-1}$ de BAP, sendo inoculados com o tamanho de $3-5 \mathrm{~mm}$, contendo de duas a quatro gemas (Oliveira et al., 2004). O ajuste do $\mathrm{pH}$, a autoclavagem e as condições de cultivo foram realizados da mesma forma relatada anteriormente. Dessa maneira, foram conduzidos seis subcultivos de 40 dias, avaliando-se as taxas de multiplicação e de contaminação dos explantes, os níveis de oxidação e de vitrificação e o estado geral das plantas. Os tratamentos foram dispostos em delineamento inteiramente ao acaso, com dez repetições, sendo as unidades experimentais constituídas por um frasco contendo cinco explantes. As taxas de multiplicação das cultivares, nos subcultivos 3 a 6 , foram comparadas pelo teste de Tukey, a $5 \%$ de probabilidade, mediante prévia transformação dos dados para $(x+0,5)^{1 / 2}$. A estimativa do número de plantas obtidas de cada cultivar foi realizada multiplicando-se as taxas de multiplicação obtidas nos seis subcultivos.

$\mathrm{O}$ enraizamento das plantas foi realizado in vitro, utilizando meio de cultura semi-sólido MS com metade da concentração dos sais e $0,5 \mathrm{mg} \mathrm{L}^{-1}$ ANA. Para essa fase, foram utilizadas todas as plantas maiores que $6 \mathrm{~mm}$, as quais foram individualizadas. Após 30 dias, as plantas que se desenvolveram, foram transplantadas em bandejas de isopor de 72 células, contendo substrato comercial Plantmax $\mathrm{HT}^{\circledR}$. As bandejas foram dispostas em túnel plástico no interior de casa de vegetação com controle de temperatura $\left(25-30^{\circ} \mathrm{C}\right)$ e de irrigação. Gradativamente, ao longo de 15 dias, a cobertura plástica foi sendo removida até completar a aclimatização (Oliveira et al., 2004).

\section{RESULTADOS E DISCUSSÃO}

$\mathrm{Na}$ fase de estabelecimento in vitro (Subcultivo 0), as cultivares Ébano, Comanche e Guarani apresentaram as maiores porcentagens de meristemas desenvolvidos, respectivamente, de $63 \%, 73 \%$ e $70 \%$. As menores foram obtidas com as cultivares Brazos (17\%), Cherokee (17\%), Tupy (17\%) e Xavante (30\%). No mês de janeiro de 2006, quando foi realizada a extração dos meristemas, as plantas-matrizes apresentavam brotações novas, estando na fase ideal para iniciar a micropropagação. A baixa porcentagem de desenvolvimento dos meristemas, com média de $41 \%$, deveu-se, provavelmente, ao material vegetal ter sido coletado do campo e não de casa de vegetação (Oliveira \& Silva, 1997).

Independentemente da cultivar, a taxa média de multiplicação foi de 6,2 plantas por subcultivo (Tabela 1). Esse resultado evidencia o adequado ajuste do meio e das condições 
de cultura e a facilidade da micropropagação da amoreira-preta. Em outras culturas, sob condições in vitro, verifica-se menor taxa de multiplicação das plantas, sendo de 3,6 para pessegueiro (Couto et al., 2004), 2,4 para bananeira (Oliveira \& Silva, 1997), 5,0 para morangueiro (Brahm \& Oliveira, 2004) e 2,9 para mandioca (Oliveira et al., 2000).

No presente trabalho, verificou-se efeito pronunciado da cultivar no desenvolvimento in vitro das plantas (Tabela 1). As taxas médias de multiplicação por subcultivo foram de 7,8 para a 'Ébano', 6,6 para 'Tupy', 6,1 para 'Cherokee', 6,1 para 'Comanche', 5,9 para 'Xavante', 5,5 para 'Brazos' e 5,4 para 'Guarani'. Esse efeito do genótipo na taxa de multiplicação já havia sido descrito em Rubus por Mayer et al. (1997) e Mezzetti et al. (2004).

Destacadamente, a cultivar Ébano apresentou o maior potencial de multiplicação in vitro, estimando-se a obtenção de 106.550 mudas por meristema inicial, após seis subcultivos de 40 dias (Figura 1). Isto também ficou evidenciado pelos resultados do teste de Tukey, a 5\% de probabilidade, ao se compararem as taxas médias de multiplicação das cultivares nos subcultivos 3 a 6 (Tabela 1). O fato de as plantas da cultivar Ébano terem apresentado as menores taxas médias de oxidação (1\%), contaminação ( $0 \%$ e vitrificação $(0 \%)$ (Tabela 2$)$, contribuíram para sua alta performance in vitro.

Após a cultivar Ébano, a 'Tupy' apresentou o maior potencial de multiplicação in vitro, ou seja, 34.022 mudas após seis subcultivos de 40 dias. Essa cultivar, que é, atualmente, a mais plantada no Brasil, já havia sido relatada como altamente responsiva in vitro por Mayer et al. (1997). Esses autores obtiveram taxa média de multiplicação de 4,5 para a cv. Tupy contra apenas 2,8 para 'Cherokee'. O maior vigor das cultivares Ébano e Tupy em relação à 'Cherokee' e à 'Comanche' também havia sido observado por Antunes et al. (2000), ao quantificarem a produção de matéria seca da parte aérea de estacas enraizadas em campo.

Em seguida e em ordem decrescente, o potencial de multiplicação foi de 24.651 mudas para a cultivar Xavante, 24.211 para 'Cherokee', 19.778 para 'Comanche', 16.335 para 'Brazos' e 14.275 para 'Guarani' (Figura 1). Pelos resultados obtidos, não se pode correlacionar o potencial de multiplicação à origem das cultivares, uma vez que a 'Brazos' é um dos parentais das cultivares Ébano, Guarani, Comanche e Cherokee, e a 'Comanche', da ‘Ébano' e da 'Tupy' (Raseira et al., 1984).

Durante o cultivo in vitro, as plantas das cultivares estudadas não apresentaram formação de calos, o que é importante para evitar a ocorrência de variação somaclonal (Oliveira et al., 2000). Conseqüentemente, não se verificou a ocorrência de mudas morfologicamente atípicas nas condições in vitro e no viveiro. No presente trabalho, foram utilizados apenas seis subcultivos para minimizar o surgimento de variantes somaclonais, conforme recomendam McPheeters \& Skirvin (1989), EPPO (2004) e Oliveira et al. (2004). Segundo McPheeters \& Skirvin (1989) e Mezzetti et al. (2004), as alterações fenotípicas mais comuns em amoreira-preta referem-se ao porte das plantas, hábito de crescimento, vigor, número de flores, fertilidade, presença e morfologia dos espinhos.

Durante a fase de multiplicação (subcultivos 1 a 6), não houve contaminação nem oxidação dos explantes das sete cultivares estudadas (Tabela 2), revelando condições adequadas de cultivo in vitro e de manipulação dos explantes. Ainda na Tabela 2, verifica-se que, somente na fase de estabelecimento in vitro, independentemente da cultivar, houve contaminação (4\%) e oxidação $(25 \%)$ dos explantes, o que era esperado em função de terem sido coletados do campo e da adaptação das cultivares às condições in vitro (Oliveira \& Silva, 1997).

A partir do quarto subcultivo, independentemente da cultivar, os explantes começaram a apresentar sintomas crescentes de vitrificação: $3 \%$ no subcultivo $4 ; 16 \%$ no subcultivo 5 , e $17 \%$ no subcultivo 6 . Esses sintomas foram mais intensos nas cultivares Comanche, Cherokee e Guarani, chegando a atingir médias de 50\%, 30\% e 30\% no $6^{\circ}$ subcultivo. Apenas na 'Ébano' não houve sintomas de vitrificação.

Neste trabalho, praticamente $100 \%$ das plantas submetidas ao enraizamento in vitro apresentaram desenvolvimento satisfatório de raízes, assim como verificaram Babic \& Neskovic (1984) ao trabalharem com outras cultivares de amoreira-preta. Deve-se destacar que essa espécie também apresenta grande facilidade de enraizamento de estacas em campo (Antunes et al., 2000), refletindo seu comportamento in vitro quanto a essa característica.

A eficiência do processo de aclimatização das plantas foi em torno de $97 \%$, sem haver variação entre as cultivares. As mudas apresentaram crescimento vigoroso em casa de vegetação, evidenciando a eficiência do sistema utilizado para alongamento, enraizamento, pegamento e desenvolvimento das mudas. Silva et al. (1995) também obtiveram alta eficiência no processo de aclimatização (96\%), refletindo a facilidade de adaptação do gênero Rubus da condição in vitro para ex vitro.

Em síntese, adotando-se a metodologia descrita e assumindo-se os mesmos índices de eficiência obtidos durante o processo de micropropagação, pode-se estimar como sendo necessários, respectivamente, $1 ; 3 ; 4 ; 4 ; 5 ; 6$ e 7 meristemas responsivos das cultivares Ébano, Tupy, Cherokee, Xavante, Comanche, Brazos e Guarani para produção de 100.000 mudas de amoreira-preta no período de 13 meses. Nesse cálculo, foram considerados 60 dias para a fase de estabelecimento in vitro, 240 dias para a multiplicação, 30 dias para o enraizamento e 60 dias para o enraizamento e a formação das mudas. 


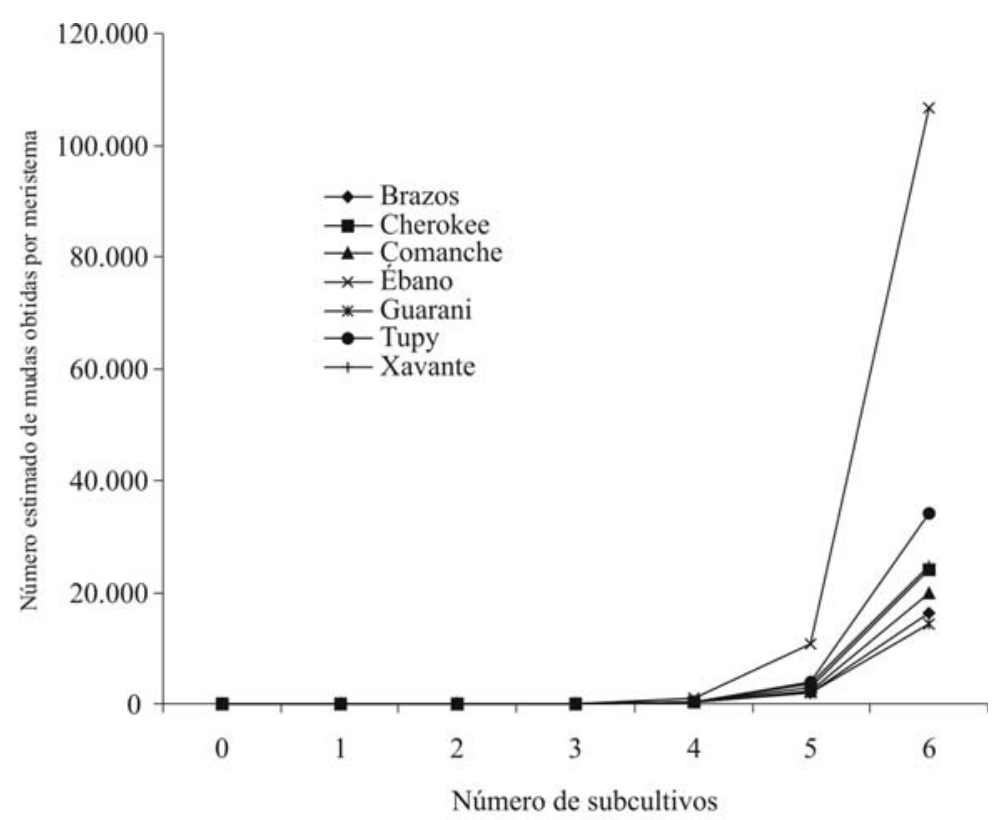

FIGURA 1 - Número estimado de mudas de sete cultivares de amoreira-preta (Rubus spp.), micropropagadas ao longo de seis subcultivos.

TABELA 1 - Taxa média de multiplicação por subcultivo de cultivares de amoreira-preta (Rubus spp.) durante a micropropagação.

\begin{tabular}{|c|c|c|c|c|c|c|c|}
\hline \multirow{2}{*}{ Cultivar } & \multicolumn{6}{|c|}{ Subcultivo } & \multirow{2}{*}{$\begin{array}{l}\text { Taxa média } \\
\text { multiplicação }\end{array}$} \\
\hline & 1 & 2 & 3 & 4 & 5 & 6 & \\
\hline Brazos & 2,3 & 3,3 & 7,7 bc & $5,8 \mathrm{e}$ & $6,1 \mathrm{c}$ & $7,9 \mathrm{bc}$ & 5,5 \\
\hline Cherokee & 1,7 & 4,4 & $8,0 \mathrm{bc}$ & $7,0 \mathrm{de}$ & $6,8 \mathrm{bc}$ & $8,5 \mathrm{~b}$ & 6,1 \\
\hline Comanche & 2,1 & 2,3 & $9,3 \mathrm{~b}$ & $7,4 \mathrm{bcd}$ & $7,0 \mathrm{bc}$ & $8,5 \mathrm{~b}$ & 6,1 \\
\hline Ébano & 2,4 & 4,4 & $10,2 \mathrm{a}$ & $10,3 \mathrm{a}$ & $9,8 \mathrm{a}$ & $9,8 \mathrm{a}$ & 7,8 \\
\hline Guarani & 2,6 & 2,6 & $5,9 \mathrm{~d}$ & 7,1 cde & $7,1 \mathrm{bc}$ & $7,1 \mathrm{c}$ & 5,4 \\
\hline Tupy & 1,6 & 4,4 & $7,7 \mathrm{bc}$ & $8,9 \mathrm{ab}$ & $8,2 \mathrm{~b}$ & $8,6 \mathrm{~b}$ & 6,6 \\
\hline Xavante & 2,7 & 3,0 & $6,8 \mathrm{~cd}$ & $8,4 \mathrm{bc}$ & $7,4 \mathrm{bc}$ & $7,2 \mathrm{c}$ & 5,9 \\
\hline Média & 2,2 & 3,5 & 7,9 & 7,8 & 7,5 & 8,2 & 6,2 \\
\hline CV (\%) & 8,0 & 11,5 & 7,1 & 6,5 & 9,7 & 4,8 & $=$ \\
\hline
\end{tabular}

'Médias seguidas de mesma letra, na coluna, não diferem entre si, pelo teste de Tukey, $5 \%$ de probabilidade. Na análise estatística, os valores foram transformados em $(x+0,5)^{1 / 2}$.

TABELA 2 - Porcentagem de explantes por subcultivo (SC) de cultivares de amoreira-preta (Rubus spp.) contaminados por fungos e/ ou bactérias $(\mathrm{C})$, com sintomas de vitrificação $(\mathrm{V})$ e de oxidação $(\mathrm{O})$ durante a micropropagação.

\begin{tabular}{|c|c|c|c|c|c|c|c|c|c|c|c|c|c|c|c|c|c|c|c|c|c|c|c|c|}
\hline \multirow[t]{2}{*}{ Cultivar } & \multicolumn{3}{|c|}{ SC 0} & \multicolumn{3}{|c|}{ SC 1} & \multicolumn{3}{|c|}{ SC 2} & \multicolumn{3}{|c|}{ SC 3} & \multicolumn{3}{|c|}{ SC 4} & \multicolumn{3}{|c|}{ SC 5} & \multicolumn{3}{|c|}{ SC 6} & \multicolumn{3}{|c|}{ Média } \\
\hline & $\mathrm{C}$ & $\mathrm{V}$ & $\mathrm{O}$ & $\mathrm{C}$ & $\mathrm{V}$ & $\overline{\mathrm{O}}$ & $\bar{C}$ & $\mathrm{~V}$ & $\mathrm{O}$ & $\mathrm{C}$ & $\bar{V}$ & $\mathrm{O}$ & $\mathrm{C}$ & $\mathrm{V}$ & $\mathrm{O}$ & $\mathrm{C}$ & $\mathrm{V}$ & $\mathrm{O}$ & $\mathrm{C}$ & $\mathrm{V}$ & $\mathrm{O}$ & $\mathrm{C}$ & $\mathrm{V}$ & $\mathrm{O}$ \\
\hline$\overline{\text { Brazos }}$ & 10 & 0 & 30 & $\overline{0}$ & 0 & 0 & 0 & 0 & 0 & 0 & 0 & 0 & 0 & 1 & 0 & 0 & 1 & 0 & 0 & 3 & 0 & 1 & 1 & 4 \\
\hline Cherokee & 0 & 0 & 50 & 0 & 0 & 0 & 0 & 0 & 0 & 0 & 0 & 0 & 0 & 5 & 0 & 0 & 10 & 0 & 0 & 30 & 0 & 0 & 7 & 7 \\
\hline Comanche & 10 & 0 & 20 & 0 & 0 & 0 & 0 & 0 & 0 & 0 & 0 & 0 & 0 & 10 & 0 & 0 & 25 & 0 & 0 & 50 & 0 & 1 & 12 & 3 \\
\hline Ébano & 0 & 0 & 5 & 0 & 0 & 0 & 0 & 0 & 0 & 0 & 0 & 0 & 0 & 0 & 0 & 0 & 0 & 0 & 0 & 0 & 0 & 0 & 0 & 1 \\
\hline Guarani & 0 & 0 & 10 & 0 & 0 & 0 & 0 & 0 & 0 & 0 & 0 & 0 & 0 & 5 & 0 & 0 & 10 & 0 & 0 & 30 & 0 & 0 & 7 & 1 \\
\hline Tupy & 0 & 0 & 30 & 0 & 0 & 0 & 0 & 0 & 0 & 0 & 0 & 0 & 0 & 1 & 0 & 0 & 1 & 0 & 0 & 3 & 0 & 0 & 1 & 4 \\
\hline Xavante & 5 & 0 & 30 & 0 & 0 & 0 & 0 & 0 & 0 & 0 & 0 & 0 & 0 & 1 & 0 & 0 & 1 & 0 & 0 & 3 & 0 & 1 & 1 & 4 \\
\hline Média & 4 & 0 & 25 & 0 & 0 & 0 & 0 & 0 & 0 & 0 & 0 & 0 & 0 & 3 & 0 & 0 & 16 & 0 & 0 & 17 & 0 & 1 & 4 & 4 \\
\hline
\end{tabular}




\section{CONCLUSÕES}

1-As cultivares de amoreira-preta apresentam variabilidade genética pronunciada quanto ao potencial de multiplicação in vitro.

2-A cultivar Ébano apresenta o maior potencial de multiplicação in vitro, seguida por 'Tupy', 'Cherokee', 'Comanche', 'Xavante', 'Brazos' e 'Guarani'.

3-O sistema de micropropagação avaliado proporciona altas taxas de multiplicação para várias cultivares de amoreirapreta, com níveis mínimos de contaminação e de oxidação das plantas.

\section{AGRADECIMENTOS}

Ao CNPq e à FAPERGS, pelo financiamento do projeto e pela concessão de bolsas.

\section{REFERÊNCIAS}

ANTUNES, L.E.C. Amora-preta: nova opção de cultivo no Brasil. Ciência Rural, Santa Maria, v.32, n.1, p.151-158, 2002.

ANTUNES, L.E.C.; CHALFUN, N.N.J.; REGINA, M.A. Propagação de cultivares de amoreira-preta (Rubus spp.) através de estacas lenhosas. Revista Brasileira de Fruticultura, Jaboticabal, v.22, n.2, p.195-199, 2000.

BABIC, V.; NESKOVIC, M. Propagation of three blackberry cultivars from small apical buds in vitro. Journal of Horticultural Science, Ashford Kent, v.59, n.2, p.183-185, 1984.

BRAHM, R.U.; OLIVEIRA, R.P. Potencial de multiplicação in vitro de cultivares de morangueiro. Revista Brasileira de Fruticultura, Jaboticabal, v.26, n.3, p.507-510, 2004.

CLARK, J.R. Blackberry: world production and perspectives. In: ENCONTRO SOBREPEQUENAS FRUTAS E FRUTAS NATIVAS DO MERCOSUL, 2., 2006, Pelotas. Palestras... Pelotas: Embrapa Clima Temperado, 2006. p.11-16.

COUTO, M.; OLIVEIRA, R.P.; FORTES, G.R.L. Multiplicação in vitro dos porta-enxertos de Prunus sp. 'Barrier' e 'Cadaman'. Revista Brasileira de Fruticultura, Jaboticabal, v.26, n.1, p.5-7, 2004.

EPPO. European and Mediterranean Plant Protection Organization. Certification schemes; pathogen-tested material of Rubus. Paris: EPPO, 2004. 9p.

MAYER, M.D.B.; PASQUAL, M.; OLIVEIRA, P.D.; MOREIRA, M.A. Efeito de diferentes reguladores de crescimento e sulfato de adenina na propagação in vitro de amora-preta. Revista Brasileira de Fruticultura, Jaboticabal, v.19, n.3, p.381-385, 1997.
McPHEETERS, K.; SKIRVIN, R.M. Somaclonal variation among ex vitro 'Thornless Evergreen' trailing blackberries. Euphytica, Wageningen, v.42, p.155-162, 1989.

MEZZETTI, B.; SAVINI, G.; CARNEVALI, F.; MOTT, D. Plant genotype and growth regulators interaction affecting in vitro morphogenesis of blackberry and raspberry. Biologia Plantarum, Prague, v.39, n.1, p.139-150, 2004.

MURASHIGE, T.; SKOOG, F. A revised medium for rapid growth and bioassays with tobacco tissue cultures. Physiologia Plantarum, Copenhagen, v.15, n.3, p.473-497, 1962.

OLIVEIRA, R.P.; SILVA, S.O. Avaliação da micropropagação comercial em bananeira. Pesquisa Agropecuária Brasileira, Brasília, v.32, n.4,p.415-420, 1997.

OLIVEIRA, R.P.; GOMES, T.S.; VILARINHOS, A.D. Avaliação de um sistema de micropropagação massal de variedades de mandioca. Pesquisa Agropecuária Brasileira, Brasília, v.35, n.12, p.2329-2334, 2000 .

OLIVEIRA, R.P.; NINO, A.F.P.; SILVA, F.O.X. Produção de mudas de amora-preta por meio de cultura de tecidos. Pelotas: Embrapa Clima Temperado, 2004. 23p. (Sistemas de Produção, 6).

RASEIRA, M.C.B.; SANTOS, A.M.; MADAIL, J.C.M. Amorapreta: cultivo e utilização. Pelotas: Embrapa/CNPFT, 1984. 20p. (Circular Técnica, 11).

SANTOS, A.M.; RASEIRA, M.C.B.; MADAIL, J.C.M. Amorapreta. 2.ed. Brasília: Embrapa-SPI; Pelotas: Embrapa-CPACT, 1997. 61p. (Coleção Plantar, 33).

SILVA, A.T.; PASQUAL, M.; ISHIDA, J.S.; ANTUNES, L.E.C. Aclimatização de plantas provenientes da cultura in vitro. Pesquisa Agropecuária Brasileira, Brasília, v.30, n.1, p.49-53, 1995. 